\title{
NUMERICAL SIMULATIONS OF BLAST LOADS FROM NEAR-FIELD GROUND EXPLOSIONS IN AIR
}

\author{
STANISŁAW DOBROCIŃSKI, LESZEK FLIS \\ Mechanical Engineering Department, Gdynia Polish Naval Academy, \\ Śmidowicza 19, 81-103 Gdynia, Poland, \\ e-mail: s.dobrocinski@amwgdynia.pl,1.flis@amw.gdynia.pl
}

\begin{abstract}
Numerical simulations of air blast loading in the near-field acting on the ground have been performed. A simplified blast model based on empirical blast loading data representing spherical and hemispherical explosive shapes has been simulated. Conwep is an implementation of the empirical blast models presented by Kingery and Bulmash, which is also implemented in the commercial code LS-DYNA based on work done by Rahnders-Pehrson and Bannister. This makes it possible to simulate blast loads acting on structures representing spherical and hemispherical explosive shapes of TNT with reasonable computational effort as an alternative to the SPH and Eulerian model. The CPU time for the simplified blast model is however considerably shorter and may still be useful in time consuming concept studies. Reasonable numerical results using reasonable model sizes can be achieved not only for modelling near-field explosions in air but most areas of geotechnical. Calculation was compared with blast SPH and Eulerian model.
\end{abstract}

Key words: near-field, blast load, numerical simulation, high explosive

\section{INTRODUCTION}

The phenomenon of the explosion is one of the issues of design impact loads. Impact load acting on the structure can be from the explosion but also from the impact or force kinematic. Energy is transferred through the centre of the structure (air, water, soil, solid) [10].

The pressure caused by an explosion, in particular the nature of the variation in time and space, depends on the type of explosive disorder transferring media properties, as well as the shape, stiffness, structural position in relation to the environment and the canter of the explosion [10].

The analysis of impact resistance pressure acting at any point of the structure is usually adopted as a single pulse. Short-term but intense loads cause the specific behaviour of the structure and require adequate methods of analysis. In this paper, based on years of experience, and shows only the latest FEA modelling techniques outbreak indicating their advantages and disadvantages [10].

Article is mainly aimed at researchers beginning with work in modeling the explosion as an aid in selecting the most adequate path for them to conduct. Implementation of the methods described in the article as presented in [14] and together with [15], [16] represents the highest level of FEM numerical modelling explosion issue.

\section{BLAST MODELING TECHNIQUES}

\section{Empirical blast load function}

The empirical blast loading function CONWEP, based on TNT data from Kingery and Bulmash [1], was implemented in LS-DYNA based on work by RandersPehrson and Bannister [2], [3]. This enables an opportunity to simulate blast loading on a Lagrangian structure without having to simulate the blast load in an Eulerian domain by using *LOAD_BLAS_ENHANCED function [3]. The blast load corresponds to the free air detonation of a spherical charge or as well as surface detonation of a hemispherical charge of TNT. The load acts on a set of predefined segments, i.e., a surface of solid elements or shell elements. The pressure $p$ that acts on a segment accounting for angle of incidence of the pressure wave, $\theta$, is determined according to

$$
p=p_{i}\left(1+\cos \theta-2 \cos ^{2} \theta\right)+p_{r} \cdot \cos ^{2} \theta
$$

where $p_{i}$ is the incident pressure and $p_{r}$ is the reflected pressure [2]. However, no shadowing, confinement or tunnel effects are included in the blast loading model, which seems to be appropriate for free air detonation of ground blast [4]. 
For the underwater analysis (UNDEX) purposes *LOAD_SSA capability allows a simple and efficient way of loading the structure to account for the effects of the primary shock wave [3]. The pressure history of the primary shockwave at a point in space through which a detonation wave passes is given as Cole's formula

$$
p(t)=p_{m} e^{-\frac{t}{\theta}}
$$

where $p_{m}$ and the time constant $\theta$ below are functions of the type and weight $W$ of the explosive charge and the distance $Q$ from the charge

$$
\begin{gathered}
p_{\text {peak }}=A\left[\frac{W^{1 / 3}}{Q}\right]^{\alpha}, \\
\theta=K_{\theta} W^{1 / 3}\left[\frac{W^{1 / 3}}{Q}\right]^{\gamma},
\end{gathered}
$$

where $A, \alpha, \gamma$, and $K$ are constants for the explosive being used.

\section{SPH simulation}

SPH is now widely used in several high strain-rate and large-deformation problems which may otherwise be difficult to simulate when using traditional mesh based approaches [11].

The name SPH includes the term "Particle". Although this is appropriate for describing the Lagrangian motion of mass points in $\mathrm{SPH}$, it is misleading because the "particles" are really interpolation points. This is best demonstrated through a simple example. Consider steel rod that is represented by a series of SPH particles, as illustrated in Fig. 1 [12].

The density at particle I can be calculated using an expression such as

$$
\rho^{\mathrm{I}}=\sum_{\mathrm{J}=1}^{\mathrm{N}} m^{\mathrm{J}} W^{\mathrm{IJ}}\left(x^{\mathrm{I}}-x^{\mathrm{J}}, h\right)
$$

where $m^{\mathrm{J}}$ - is the mass of particle $\mathrm{J}, W^{\mathrm{IJ}}$ - is a weighting function (Kernel B-spline), $x$ - is the position of the centre of a particle, $h$-is known as the smoothing length or particle size.

Therefore, to calculate the value of a function at particle I (in this case, density) we sum the value of the function at all neighbouring particles (interpolation points J1, J2, I, J3, J4) multiplied by a weighting function (the Kernel function) [12].

Hence, the SPH particles are not simply interacting mass points but they are interpolation points from which values of functions, and their derivatives, can be estimated at discrete points in the continuum. In SPH, the discrete points at which all quantities are evaluated are placed at the centre of the SPH particles [12].

For comparison, in the grid based Lagrange processor, the interpolation (sampling) points are defined at the corner nodes while the discrete points at which functions are evaluated are placed at the cell centre (for density, strain rate, pressure, energy, stress) or the cell nodes (for displacement, velocity, force) [12].

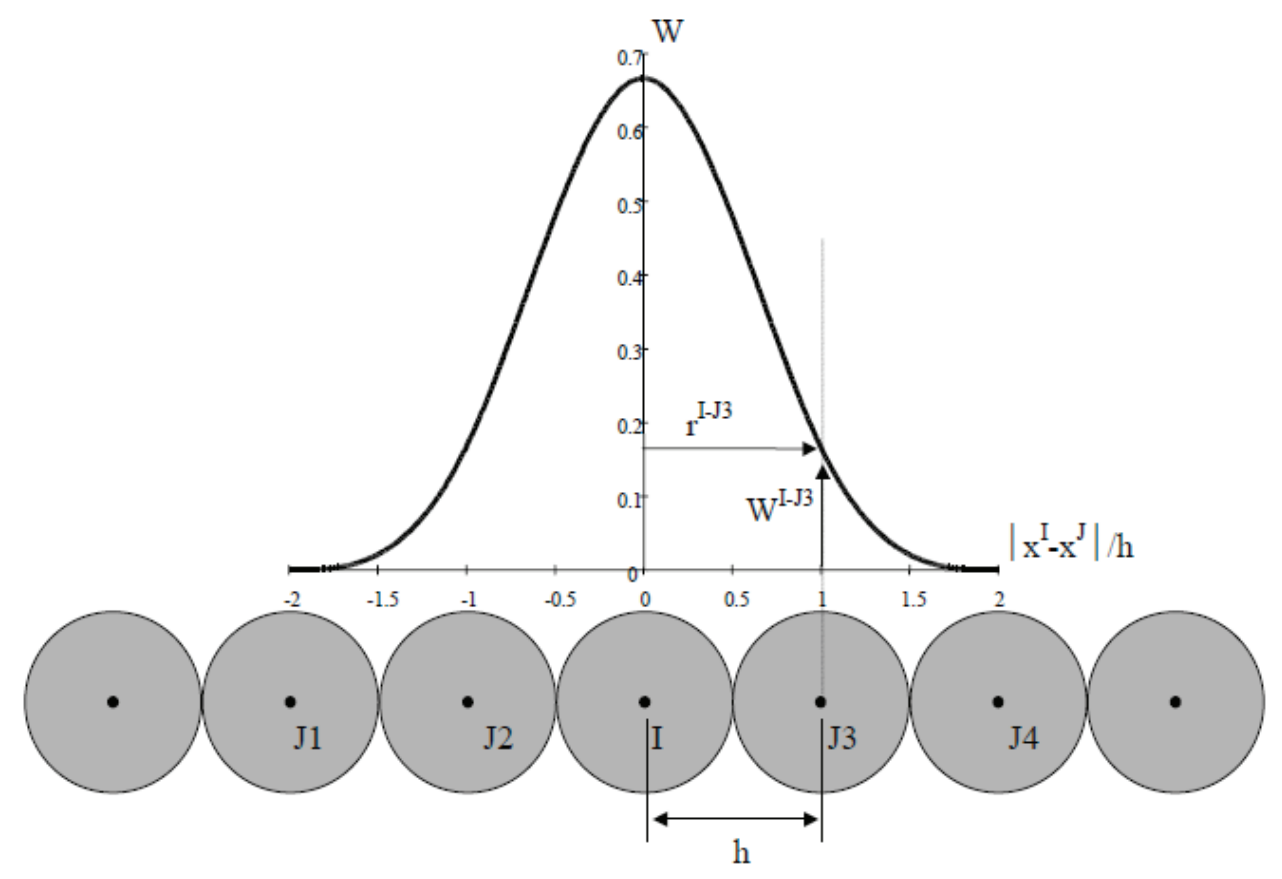

Fig. 1. Kernel density example [12] 
In $\mathrm{SPH}$, the basic steps used in each calculation cycle, as implemented in AUTODYN-2D \& 3D, are shown in Fig. 2. The calculation cycle is similar to that for a Lagrange zone, except for steps where a Kernel approximation is used [12].

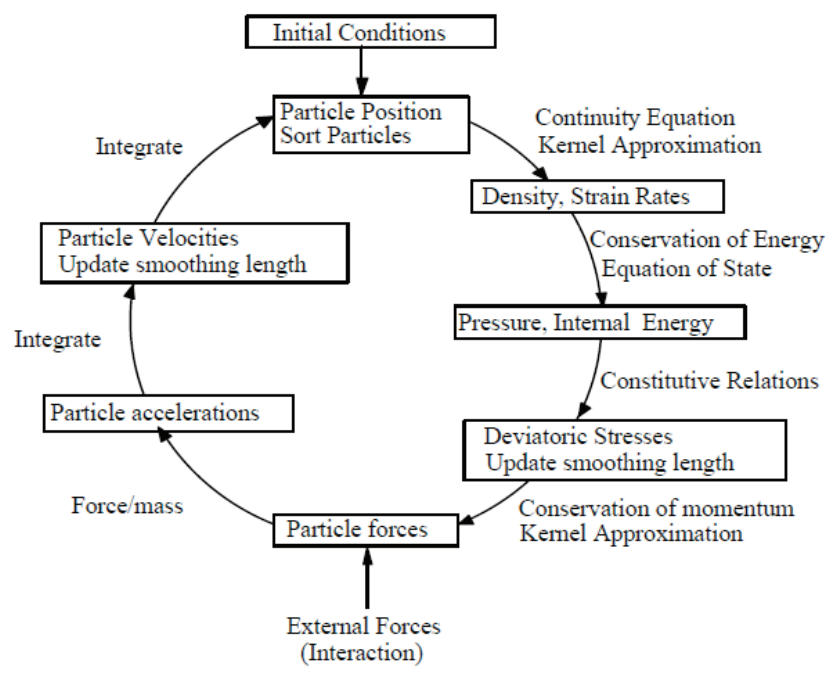

Fig. 2. Computational cycle for standard SPH [12]

Kernel approximations are used to compute forces from spatial derivatives of stress and spatial derivatives of velocity are required to compute strain rates. In addition, SPH requires a sort of the particles at least once every cycle in order to locate current neighbouring particles [12].

\section{MMALE simulation}

LS-DYNA contains a Multi-Material Arbitrary Lagrangian Eulerian (MMALE) formulation that allows for different materials such as steel and air to be present in the same element. This is particularly useful for problems where multiple gases are mixing or where the boundary between a gas and a fluid with large deformations needs to be modelled. This formulation can contain a mixture of fluids moving through an Eulerian mesh that is also moving relative to a fixed reference frame [13].

MMALE formulation will be utilized to simulate explosives in an Eulerian domain with an equation of state (EOS). The explosive agent needs to be defined as a separate material inside the Eulerian domain, thus a multilateral Euler formulation needs to be employed to properly describe the system behaviour. Because of the almost discontinuous pressure changes when the blast wave propagates in the Eulerian mesh, an extremely small element size is required to properly describe the blast wave behaviour. An MMALE formulation is therefore preferred because it can refine the mesh close to the pressure front as the wave is propagating forward and will lead to a more accurate solution [13].

\section{MATERIAL AND ENVIRONMENT MODELING}

\section{Air}

The air is modelled as an ideal gas [3] using *MAT NULL material model with the linear polynomial equation of state (EOS). The pressure is expressed by

$$
\begin{aligned}
p= & C_{0}+C_{1} \mu+C_{2} \mu^{2}+C_{3} \mu^{3}+C_{4} \mu^{4} \\
& +\left(C_{4}+C_{5} \mu++C_{6} \mu^{2}\right) E_{0}
\end{aligned}
$$

where $E_{0}$ is the initial internal energy per initial volume, $C_{0}, C_{1}, C_{2}, C_{3}, C_{4}, C_{5}$, and $C_{6}$, are constants, and $\mu=\frac{\rho}{\rho_{0}}-1$, where $\frac{\rho}{\rho_{0}}$ is the ratio of current density to initial density.

The linear polynomial equation represents an ideal gas with the gamma law EOS, in which $C_{0}=C_{1}=C_{2}$ $=C_{3}=C_{6}=0$ and $C_{4}=C_{5}=\gamma-1$ where $\gamma$ is the ratio of specific heat at constant pressure per specified heat at constant volume. The pressure is then denoted by

$$
p=(\gamma-1) \frac{\rho}{\rho_{0}} E_{0}
$$

where $\gamma$ is defined an adiabatic constant for air behaving as an ideal gas, it is ratio between the specific heat at constant pressure and volume, estimated value is 1.4 at small overpressures. At larger pressures and higher temperatures, the air starts to ionize and dissociate, and the property of the gas changes so the ratio of specific heats is no longer constant [7]. Albeit high overpressures will be reached in the near-field, it is here assumed that $\gamma=1.4$. With initial density $1.169 \mathrm{~kg} / \mathrm{m}^{3}\left(1.29 \mathrm{~kg} / \mathrm{m}^{3}\right)$, the initial pressure is 1 bar which results in an initial internal energy $E_{0}$ of $250 \mathrm{~kJ} / \mathrm{m}^{3}(0.25 \mathrm{MPa})$ [4], [7].

\section{Explosive}

The explosive is modelled as a high explosive material with a Jones-Wilkins-Lee (JWL) form of equation of state. A combined programmed burn and beta burn model determines when an explosive element is detonated based on the initial density $\rho_{0}$, detonation pressure $P_{C J}$ and detonation velocity $D[3]$. The 
programmed burn model defines at what time an explosive element is detonated based on a given detonation point and the detonation velocity. The beta burn model allows an explosive element to be detonated due to compression, i.e., when the pressure in an explosive element reaches $P_{C J}$. When the criteria for detonation of an explosive element are achieved based on either the programmed or beta burn model, the energy is then released with the pressure defined according to the three term JWL equation of state as

$$
p=A \cdot\left(1-\frac{\omega}{R_{1} \cdot v}\right) e^{\left(-R_{1} \cdot v\right)}+B \cdot\left(1-\frac{\omega}{R_{2} \cdot v}\right) e^{\left(-R_{2} \cdot v\right)}+\frac{\omega \cdot E}{v}
$$

where $A, B, R_{1}, R_{2}$ and $\omega$ are material constants, $v=\rho_{0} / \rho$ is the relative volume and $E$ is the internal energy per unit reference volume. The constants are usually empirically determined with cylinder tests or in combination with thermos-chemical simulations of the reaction products. The material and JWL parameters for explosive material are given in Table 1 [4]. through laboratory tests and/or equations in the material manual Fig. 3 [8].

\section{Structural materials}

In modelling by using the Finite Element Method (FEM), a constitutive equation is one of the most significant elements, since its task is to describe material properties. The Johnson-Cook $(\mathrm{J}-\mathrm{C})$ constitutive equation is employed to resolve numerical problems in which we encounter questions connected with high speed, with high strain rate and with high plastic strain what takes place while blast explosion issue.

$$
\sigma=\left(A+B \cdot \varepsilon^{n}\right)\left[1+C \cdot \ln \left(\frac{\dot{\varepsilon}}{\dot{\varepsilon}_{0}}\right)\right]\left[1-\left(T^{*}\right)^{m}\right]
$$

where

$$
\begin{aligned}
& \sigma-\text { von Mises flow stress, } \\
& A-\text { yield stress, } \\
& B-\text { effects of strain hardening, } \\
& \varepsilon-\text { equivalent, effective plastic strain, } \\
& n-\text { exponent strengthen, }
\end{aligned}
$$

Table 1. Material- and JWL-parameters for the plastic explosive $\mathrm{m} / 46$ [4]

\begin{tabular}{|c|c|c|c|c|c|c|c|c|}
\hline$\rho\left(\mathrm{kg} / \mathrm{m}^{3}\right)$ & $D\left(\mathrm{~m} / \mathrm{s}^{2}\right)$ & $P_{C J}(\mathrm{GPa})$ & $A(\mathrm{GPa})$ & $B(\mathrm{GPa})$ & $R_{1}(-)$ & $R_{2}(-)$ & $\omega(-)$ & $E_{0}\left(\mathrm{~kJ} / \mathrm{cm}^{3}\right)$ \\
\hline 1500 & 7680 & 21.15 & 759.9 & 12.56 & 5.1 & 1.5 & 0.29 & 7.05 \\
\hline
\end{tabular}

\section{Soil material model}

By evaluating several material models in LS-DYNA, *MAT FHWA SOIL model was identified as a suitable soil model that includes strain softening, kinematic hardening, strain rate effects, element deletion, excess pore water effects and stability with no soil confinement [8], [9]. This material model requires the main parameters of mass density, specific gravity, bulk modulus, shear modulus and moisture content. These soil parameters are generally determined through laboratory tests. Parameters required for defining strain softening, kinematic hardening, strain rate effects and pore water effects can be evaluated
$C$ - strain rate constant,

$\dot{\varepsilon}-$ strain rate,

$\dot{\varepsilon}_{0}-$ threshold strain rate,

$\dot{\varepsilon}^{*}=\frac{\dot{\varepsilon}}{\dot{\varepsilon}_{0}}-$ dimensionless plastic strain rate,

$T^{*}$ - homologous temperature,

$m$ - temperature exponent.

The authorial computer program J_C ICEC v.1.0, presented in Fig. 4, enables the determination, interpretation and visual mark up of all coefficients of equation (9). The coefficients are entered into the FEM solver, which shows the physical signification of executed computer simulation.

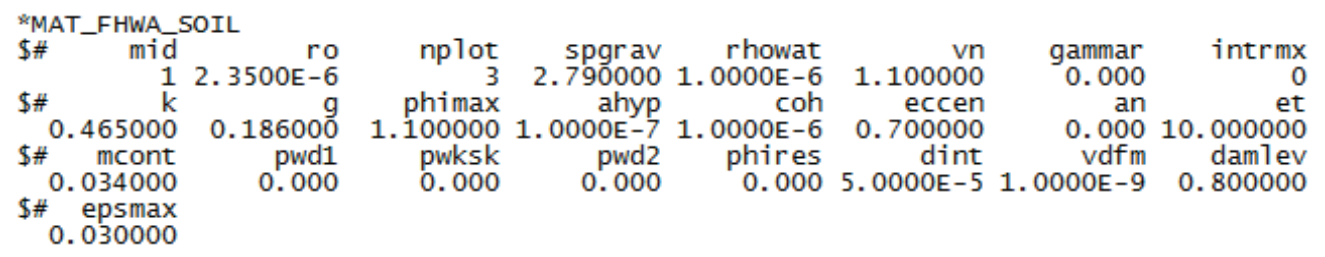

Fig. 3. Parameters of soil model in LS-DYNA format 

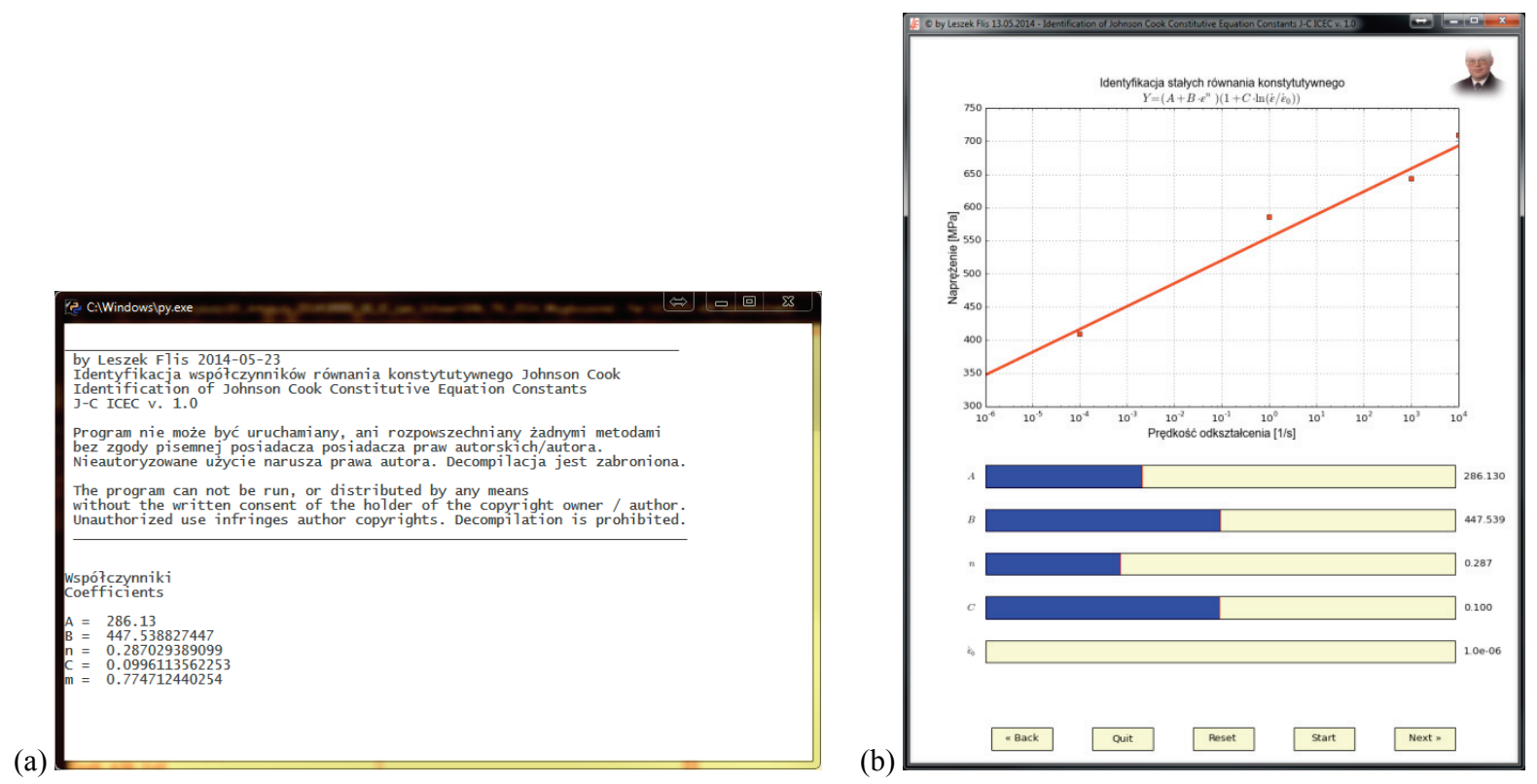

Fig. 4. The coefficients of equation (9): (a) assigned by using author's program J_C ICEC v. 1.0 [6],

(b) stress straight in strain rate function as an approximation of experimental results assigned by equation (9)

\section{NUMERICAL SIMULATION RESULTS}

Simulation of the explosion in any case showed in the article considered the same scenario. Steel plate with dimensions of $1 \mathrm{~m} \times 1 \mathrm{~m}$ is slightly recessed in the ground and above it are placed TNT explosives with a mass of $1 \mathrm{~kg}$ very close to the ground. Around the components involved is air. Figure 5 presents one quarter of the system, with visible planes of symmetry. TNT load is placed in the centre of the system.

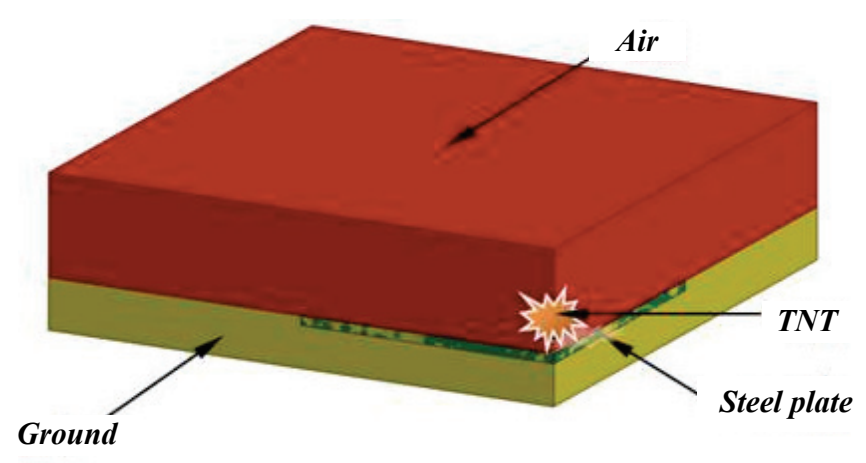

Fig. 5. System considered in the simulation of explosion

In all simulation techniques we can obtain similar results and only the user can decide which technique to use. Time consumed to carry out the simulation strongly depends on simulation technique used.

\section{Lagrangian simulation (CONWEP)}

The advantage of this solution is the possibility of estimating ascending and reflected pressures in relation to the structure that can be seen in Fig. 6 .

The method is most often used if you want to check the structural integrity of the explosion load. The LS-DYNA program offers exceptional *BLASFOR DATABASE where there are stored waveforms generated in the air pressure on the charge of TNT. The uniqueness of this approach means that we don't need model the air, what speeds up the calculation.

\section{Smoothed-particle hydrodynamics simulation (SPH)}

Smoothed-particle hydrodynamics simulation method (SPH) is very often used to show the movement of any fraction, for example, explosives material or ground, Fig. 7.

\section{Multi-Material Arbitrary-Lagrangian-Eulerian simulation (MMALE)}

The MM-ALE method combines the Lagrangian and Eulerian techniques to address both the fluid and structural dynamics of an event, Figs. 8 and 9.

The ALE technique is a useful method for explosion analysis. It allowed direct modelling of the explosion. Overall, the results indicate that the ALE technique can effectively examine structural damage after explosion, and can be applied quantitatively to real structural design. 


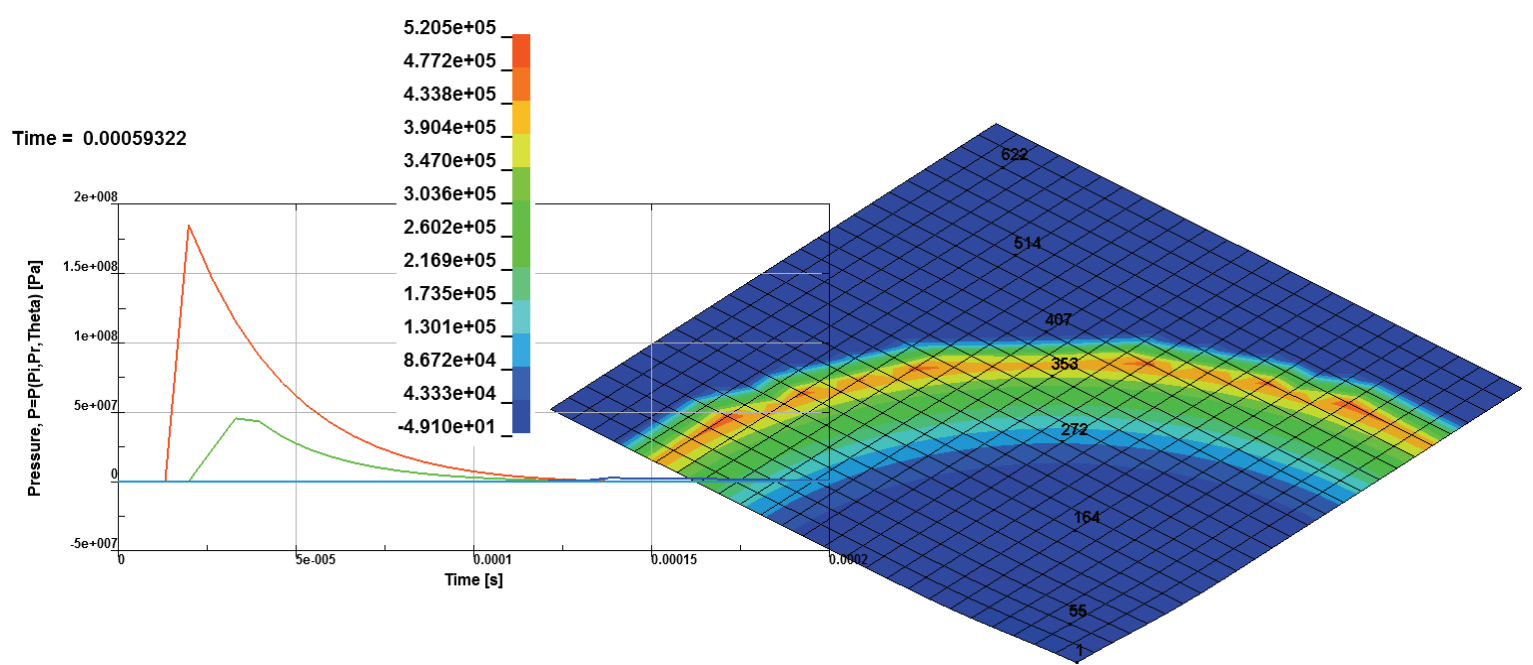

Fig. 6. TNT explosion in Lagrangian domain and the graph of the maximum pressure in the canter of the steel plate

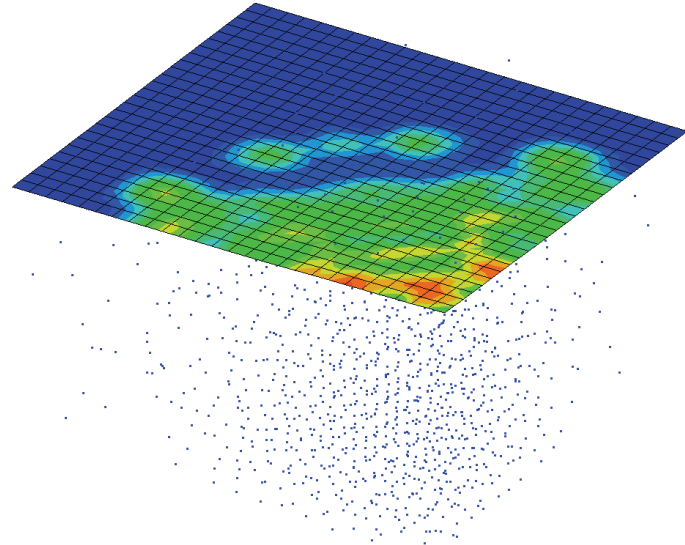

Fig. 7. TNT fraction movement (a) and (b) equivalent stress in the steel plate

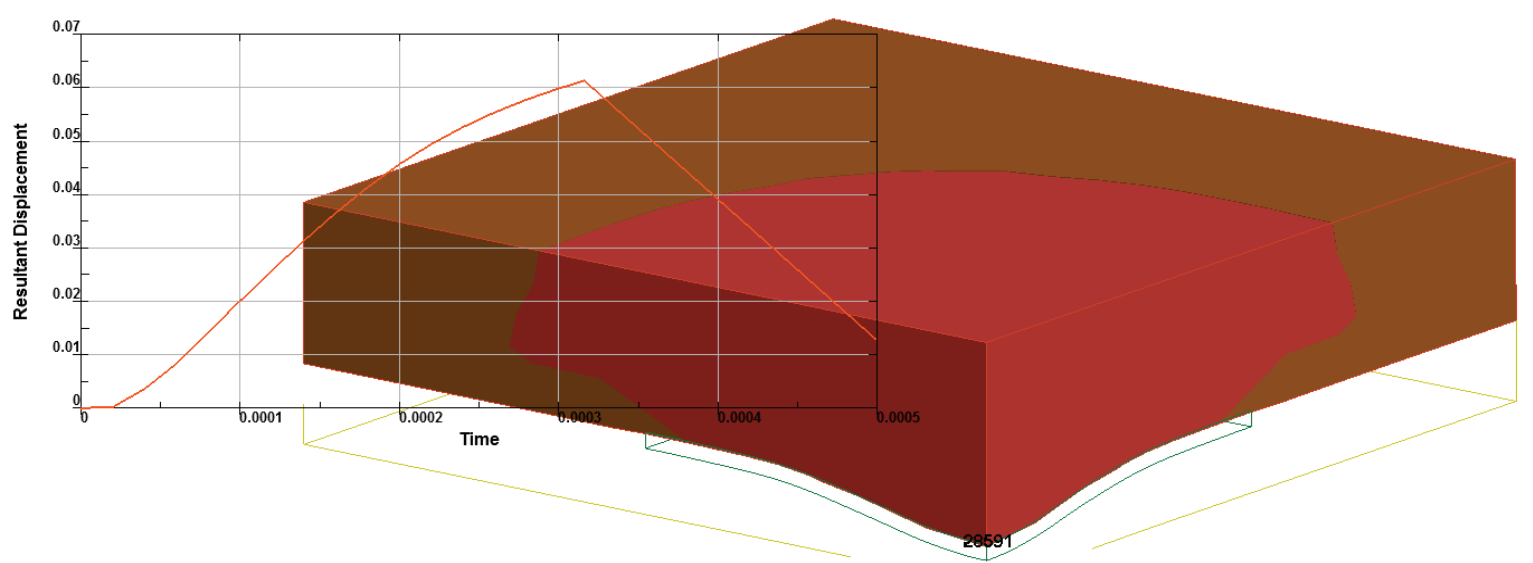

Fig. 8. ALE fluid group interface used to identification of pressure distribution in air domain action on the solid plate and ground 


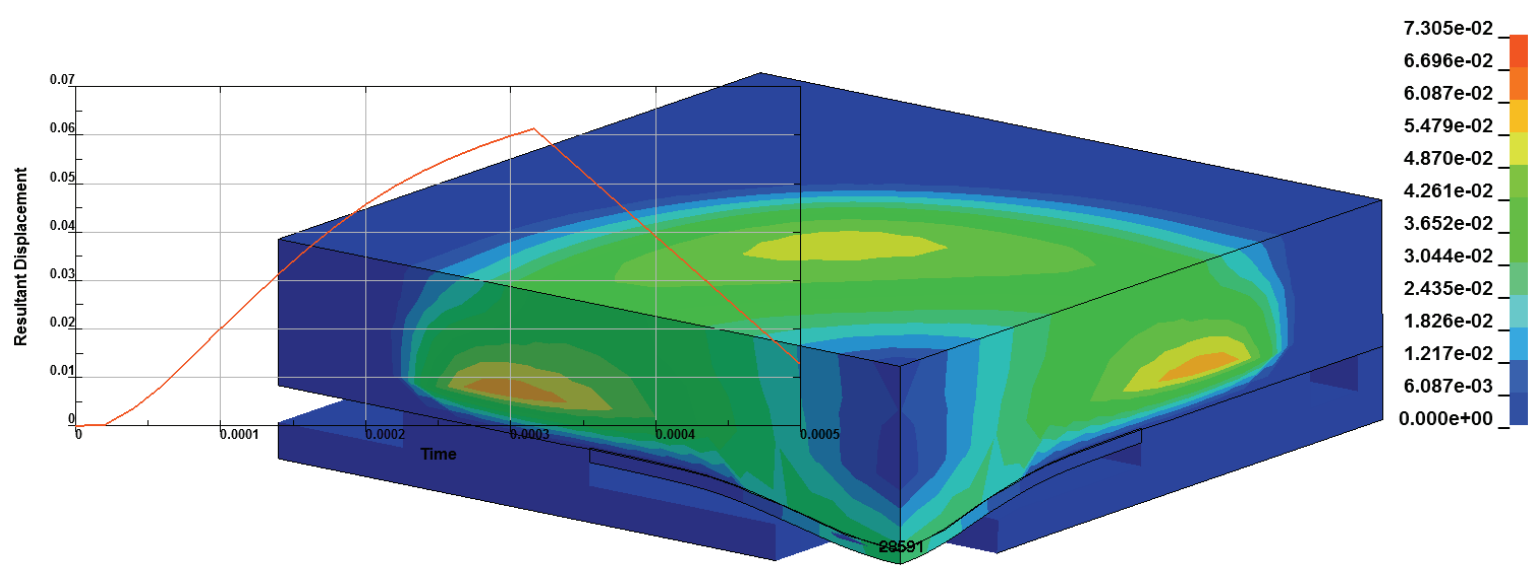

Fig. 9. Displacement in steel plate examined during explosion simulation

\section{CONCLUSION}

Three numerical modelling techniques of CONWEP, MMALE and SPH have been presented in this paper for simulating explosion using an advanced generalpurpose commercial software LS-DYNA.

All simulations show that there are many possibilities to gain knowledge about the effects of explosion without carrying out an experiment. The CONWEP simulation is widely accepted as engineering predictions for determining free-field pressures and loads on structures and form the basis of the US Conventional Weapons Effects Programme (CONWEP) software. The method is disadvantageous in that the blast wave form is not correct inside the fireball (detonation products) or a scaled distance of about $1 \mathrm{~m} / \mathrm{kg}^{1 / 3}$ for TNT.

For close-in $(<\sim 3$ charge radius) or contact detonation, MM-ALE is the only method giving reasonable results. For close-in blast, the sudden decrease in the pressure wave form is likely because the location is within the fireball (detonation products). Basically, true "air blast" only exists outside the fireball. Inside the fireball the rapidly expanding and cooling detonation products have near zero pressure compared to the air blast that past the tracer particle a few microseconds before. This rapid decrease in pressure is physical, i.e., observed in experiments, and not an artefact of MM-ALE.

\section{ACKNOWLEDGEMENTS}

Calculations were carried out at the Academic Computer Centre in Gdańsk.

\section{REFERENCES}

[1] Kingery C.N., Bulmash G., Airblast parameters from TNT spherical air burst and hemispherical surface burst, ARBRLTR-02555. MD: U.S. Army Ballistic Research Laboratory, Aberdeen Proving Ground, 1984.

[2] RANDERs-PehrSON G., BANNISTER K., Airblast loading model for DYNA2D and DYNA3D, ARL-TR-1310, Army Research Laboratory, 1997.

[3] LS-DYNA ${ }^{\circledR}$ KEYWORD USER'S MANUAL VOLUME II Material Models. 01/02/15 (r:5991) LS-DYNA Dev, Livermore Software Technology Corporation (LSTC), 2015.

[4] ZaKrisson B., WiKMAN B., HäGgBlad H., Numerical simulations of blast loads and structural deformation from nearfield explosions in air, International Journal of Impact Engineering, 2011, 38, 597-612.

[5] Johnson G.R., CoOK W.H., A constitutive model and data for metals subjected to large strains, high strain rates and high temperatures, Proceedings of the 7th International Symposium on Ballistics, The Hague, The Netherlands, 23 Apr. 1983.

[6] Flis L., SPERSKi M., Badania odporności oston warstwowych zbudowanych ze stali kadlubowych na ostrzat pociskami 12,7 mm, ZN AMW nr 4 Gdynia, 2013.

[7] Sonntag R.E., Borgnakke C., Van Wylen G.J., Fundamentals of thermodynamics, 6th ed., Wiley, Cop., New York, 2003.

[8] LewIS B., Manual for LS-DYNA Soil Material Model 147, Federal Highway Administrator, McLEAN, VA, publication No. FHWA-HRT-095 (2004).

[9] Arulmoli K., Muraleetharan M., Hossain M., Velacs verification of liquefaction analyses by centrifuge studies laboratory testing program soil data report, Tech. rep., The Earth Technology Corp., Project No. 90-0562. Irvine, California (March 1992).

[10] DoBRociŃSKI S., Stabilność rozwiazań zagadnień odporności udarowej konstrukcji, Biblioteka Problemów Eksploatacji, AMW, Gdynia 2000.

[11] http://blog2.d3view.com/sph-contact-definitions/

[12] ANSYS, AUTODYN $®$, Explicit Software for Nonlinear Dynamics, SPH User Manual \& Tutorial, Revision 4.3, Century Dynamics, 2005.

[13] Andersen K.H., Børsum Hernandez F., Numerical Simulations of Docol 600 DL Steel Plates Subject to Blast 
Loading, Department of Structural Engineering, NTNU, Trondheim, 2013.

[14] Baranowski P., MaŁachowski J., Numerical study of selected military vehiclechassis subjected to blast loading in terms of tire strength improving, Bulletin of the Polish Academy of Sciences, Technical Sciences, Vol. 63, No. 4, 2015.
[15] Mazurkiewicz Ł., MaŁachowski J., Baranowski P., Blast loading influence on load carrying capacity of I-column, Engineering Structures, 104, 2015, 107-115.

[16] Mazurkiewicz Ł., MaŁachowski J., Baranowski P., Optimization of protective panel for critical supporting elements, Composite Structures, 134, 2015, 493-505. 